\title{
PRÁTICAS SUSTENTÁVEIS VOLTADAS À GREEN LOGISTIC: ESTUDO MULTICASO EM EMPRESAS DE COSMÉTICOS
}

\author{
Sustainable practices related to Green Logistic: Multicase study in \\ cosmetics companies
}

Mariliza Rech

E-mail: rechmariliza@gmail.com

Mestra em Ciências Contábeis pela Universidade do Vale do Rio dos Sinos; Especialista em Controladoria pela Universidade Federal do Rio Grande do Sul. https://orcid.org/0000-0001-7349-4425

Débora Gomes de Gomes

E-mail: debora_furg@yahoo.com.br

Pós-doutora em Ciências Contábeis pela Universidade do Vale do Rio dos Sinos; Doutora em Ciências Contábeis e Administração pela Fundação Universidade Regional de Blumenau; Professora na Universidade Federal do Rio Grande.

Endereço para contato: Avenida Itália, Km 08, s/n, Campus Carreiros, 96203-900, Rio Grande, Rio

Grande do Sul, Brasil. https://orcid.org/0000-0002-7955-0958

Valmor Reckziegel

E-mail: vreckziegel@yahoo.com.br

Doutor em Administração pela Universidade Nove de Julho; Mestre em Ciências Contábeis pela Universidade do Vale do Rio dos Sinos; Professor na Universidade Estadual do Oeste do Paraná. https://orcid.org/0000-0002-9985-3913

Marcos Antônio de Souza

E-mail: souza.marcosas@gmail.com

Doutor em Controladoria e Contabilidade pela Universidade de São Paulo; Mestre em Administração pela Universidade Metodista de São Paulo; Professor visitante na Universidade

Federal de Uberlândia. https://orcid.org/0000-0003-3661-1607

Artigo recebido em 5 de fevereiro de 2019. Aceito em 15 de outubro de 2019. 


\section{Resumo}

Este estudo aproxima os temas de sustentabilidade e Green Logistic, com o objetivo de analisar quais práticas de sustentabilidade, voltadas à Green Logistic, são evidenciadas pelas três maiores empresas de cosméticos atuantes no Brasil. Para tal, foi realizado um estudo básico, multicaso, descritivo e documental, com abordagem qualitativa, por meio de análise de conteúdo dos relatórios de administração e de sustentabilidade, dos exercícios sociais de 2014 a 2018, das empresas Avon, o Boticário e Natura. Os resultados da pesquisa demonstraram que as três empresas analisadas evidenciam práticas de sustentabilidade voltadas à Green Logistic, especialmente com relação à redefinição de processos, de toda a cadeia produtiva e de distribuição; redução de gases de efeito estufa; uso de outros modais de transporte; parcerias com transportadoras, cadeia de fornecimento, operadores logísticos e terceiros; redução e otimização na distribuição dos produtos; logística reversa; e redução das pegadas de carbono.

Palavras-chave: Sustentabilidade. Green Logistic. Cosméticos.

\section{Abstract}

This study approaches the themes of sustainability and Green Logistic, with the objective of analyzing which sustainability practices, focused on Green Logistic, are evidenced by the three largest cosmetic companies operating in Brazil. To do this, a basic, multivariate, descriptive and documentary study was carried out, with a qualitative approach, through analysis of the content of the management and sustainability reports for the 2014 to 2018 fiscal years of Avon, o Boticário and Natura. The results of the research demonstrated that the three companies analyzed show sustainability practices focused on Green Logistic, especially in relation to the redefinition of processes, of the entire production chain and of distribution; the reduction of greenhouse gases; the use of other modes of transport; partnerships with carriers, the supply chain, logistics operators and third parties; reduction and optimization of product distribution; reverse logistic; and reduction of carbon footprints.

Keywords: Sustainability. Green Logistic. Cosmetics.

\section{INTRODUÇÃO}

O meio ambiente e os impactos das atividades empresariais têm sido objeto de pesquisas acadêmicas, conforme Corrêa, Souza, Ribeiro, e Ruiz (2012), com abordagem e foco em modelos alternativos e ações que resultem em melhorias de processos e reduções de danos ao meio ambiente, visando melhorar a relação do homem e a vida no Planeta. Pesquisas dessa natureza focam na constante preocupação com o equilíbrio entre o desenvolvimento econômico e os seus impactos sobre a natureza, porque, se de um lado há o reconhecimento de que a geração de riqueza é importante para o crescimento econômico, por outro, tem-se os dejetos e a degradação ambiental que o desenvolvimento acarreta.

Para Wang e Gupta (2012), a crescente preocupação dos efeitos ambientais no Planeta, oriundos da atividade humana, tem levado muitas empresas e governos a investirem em pesquisas, procurando reduzir seus elementos poluentes, promovendo uma evolução nas 
práticas de sustentabilidade. Os autores acrescentam que os governos passaram a impor normas ambientais e novas diretrizes para as empresas.

De outro modo, Ferreira, Pires, Beltrão, Ferreira, Souza, \& Campos (2011) destacam que houve a mudança na cultura de consumo, em que os consumidores passaram a preferir produtos que degradam menos o meio ambiente. Segundo esses autores, a exigência do consumidor passou a ser para o produto "ecologicamente correto", obrigando os fabricantes a integrarem práticas de sustentabilidade para a sua produção.

De acordo com Okado e Quinelli (2016), o futuro é uma inquietação constante que circunda a sociedade humana, considerando as inúmeras notícias a respeito do aquecimento global e suas consequências para a vida na Terra. Acrescentam que essa preocupação se pauta na desesperadora aceitação de que se nada for feito pelo Planeta, as consequências serão irreversíveis. Entre as agendas de debate climáticos, há de se destacar a mais recente criada na 70 Assembleia Geral das Nações Unidas, em setembro de 2015, e em substituição aos Objetivos de Desenvolvimento do Milênio (ODMs), evento em que foram estabelecidos os Objetivos de Desenvolvimento Sustentável (ODS), com medidas e agenda para até o ano de 2030, incluindo também medidas urgentes e de menor prazo.

Para Bowersox, Closs, e Cooper (2014), seguindo as exigências governamentais e sociais, a responsabilidade das empresas passou a ser considerada do começo ao fim do processo, ou seja, quem produz deve também se responsabilizar pelo destino final do produto gerado. Para os autores, como consequência desse novo processo, para se manterem atuantes, as empresas precisaram tornar-se mais dinâmicas e competitivas via participação mais ampla em todo o processo, contemplando desde a origem até o destino de seus produtos.

Buscando atender a essas e outras exigências mundiais de comprometimento empresarial, além das de mercado e legais, a logística, que até então focava na gestão econômica das organizações, passou a considerar em seu processo também essas maiores exigências, de responsabilidade ambiental em seu processo (Srivastava, 2007). Como resultado, nasceu a vertente da logística que passou a considerar os aspectos e impactos causados pelas suas atividades sobre a comunidade e a sustentabilidade ambiental, denominada Green Logistic.

Nesse contexto, a Green Logistic abrange diversas práticas de sustentabilidade. Srivastava (2007) destaca que as empresas buscam o gerenciamento dos custos resultantes do processo logístico como forma de reduzir seus custos totais, e, também, para obter melhores resultados, prevendo os aspectos e impactos ambientais envolvidos e direcionando ações preventivas.

Diversos estudos têm sido desenvolvidos sobre a Green Logistic. Ubeda, Arcelus, e Faulin (2011) avaliaram que a alta competitividade entre as empresas fez aumentar o interesse na Green Logistic. Wang, Lai, e Shi (2011) sugeriram um modelo de otimização com múltiplos 
objetivos para a cadeia de abastecimento, considerando investimentos em equipamentos el ou tecnologias para reduções de Green Logistics Costs de transporte e movimentação. Após implantadas as alterações, os autores examinaram reduções nas emissões de $\mathrm{CO}_{2}$ geradas por instalações de produção e distribuição.

Conforme dados da Associação Brasileira da Indústria de Higiene Pessoal, Perfumaria e Cosméticos (ABIHPEC, 2018), entre os diversos segmentos que tiveram suas operações influenciadas pelas práticas de sustentabilidade e pela Green Logistic, o de higiene pessoal, perfumaria e cosméticos apresentou crescimento acima da economia em 2017. De acordo com a ABIHPEC (2018), o mercado nacional é apontado como o quarto maior do mundo, liderado pelos Estados Unidos da América (EUA), seguido pela China e pelo Japão. O Brasil apresentou o faturamento de R\$102,5 bilhões, com exportação de US\$98,3 milhões para 102 países.

Analisando-se a cadeia produtiva, desde a aquisição das matérias-primas até a entrega ao cliente final, o segmento de perfumaria adota a Green Logistic nas suas atividades. Considerando o exposto, este estudo busca responder à seguinte questão de pesquisa: quais práticas de sustentabilidade, voltadas à Green Logistic são evidenciadas pelas três maiores empresas de cosméticos atuantes no Brasil? Isto posto, o objetivo desse estudo é analisar quais práticas de sustentabilidade, voltadas à Green Logistics, são evidenciadas pelas três maiores empresas de cosméticos atuantes no Brasil, no período de 2014 a 2018.

A representatividade das questões ambientais frente às mudanças socioeconômicas, somadas à necessidade do gerenciamento dos custos logísticos como diferencial competitivo, conforme pesquisado por Donato (2008), sinalizam a importância deste estudo. Como segundo argumento, considera-se a representatividade econômica do segmento estudado. Por fim, conforme busca realizada na base de dados EBSCOHost e de periódicos da Coordenação de Aperfeiçoamento de Pessoal de Nível Superior (Capes), identificou-se que são escassos os estudos realizados. Dada essa escassez, torna-se relevante fomentar a pesquisa no tema abordado e no segmento estudado.

Para atingir seu objetivo, o artigo está estruturado em cinco seções, considerando-se esta seção de introdução. Na segunda seção dois é apresentada a revisão de literatura de suporte ao estudo; na terceira, descrevem-se os procedimentos de natureza metodológica empregados no estudo; na quarta, são apresentadas as análises de dados e a discussão dos resultados. Finaliza-se, na quinta seção, com as considerações finais do estudo. 


\section{REVISÃO DA LITERATURA}

\subsection{SUSTENTABILIDADE}

A busca pela redução e controle dos poluentes gerados pela atividade empresarial está inserida no tema sustentabilidade, conforme pronunciamento da Comissão Mundial sobre o Meio Ambiente e Desenvolvimento (CMMAD, 1988), e tem evoluído via discussões sobre a preservação do meio ambiente e a melhoria das condições sociais e econômicas da sociedade. Segundo a CMMAD (1988), as discussões internacionais a respeito de ações prómeio ambiente e prevenção de desastres envolvendo poluentes iniciaram no século XX.

Gupta e Desai (2011) destacam que a Revolução Industrial incrementou a poluição e o consumo dos recursos naturais, originando inúmeros problemas para o meio ambiente, visto que a natureza não se recupera na mesma velocidade da degradação que sofre. Segundo os pesquisadores, o modelo econômico mundial que promove uma produção de bens de consumo cada vez maior esbarra na questão da renovação finita e limitada dos recursos.

Um retrospecto sobre a evolução de ações promovidas para a criação de uma agenda de debates e propostas de ações que promovam a sustentabilidade global é apresentado por Guerra e Schmidt (2016). Os autores apresentam um resumo dos principais movimentos ocorridos nas diversas conferências da ONU a respeito da sustentabilidade, destacando: em Estocolmo (Conferência das Nações Unidas sobre Ambiente Humano, em 1972), no Rio de Janeiro (Conferência das Nações Unidas para o Ambiente e Desenvolvimento, em 1992), em Joanesburgo (Conferência Mundial para o Desenvolvimento Sustentável, em 2002) e novamente no Rio de Janeiro (Rio+20, em 2012).

Guerra e Schmidt (2016) citam dois eventos ocorridos mais recentemente, relacionados aos novos Objetivos de Desenvolvimento Sustentável (ODS) da ONU e outro relacionado à Convenção-Quadro das Nações Unidas sobre Alterações Climáticas. Referem-se à Cimeira (ou reunião de cúpula) das Nações Unidas sobre Desenvolvimento Sustentável (Nova York, em 2015) e à $21^{a}$ Conferência das Partes-COP21 (Paris, em 2015).

Os objetivos de desenvolvimento sustentável após 2015 representaram avanços na definição de metas claras e em um prazo menor, até 2030. Conforme a Organização das Nações Unidas (2019), trata-se de uma agenda mundial com 17 objetivos, 169 metas e mais de 300 indicadores, que darão continuidade aos ODMs para o período de 2015 a 2030. Os objetivos de sustentabilidade estão apresentados na Figura 1: 


\section{ERRADICACAO \\ DAPOBREZA \\ irition}
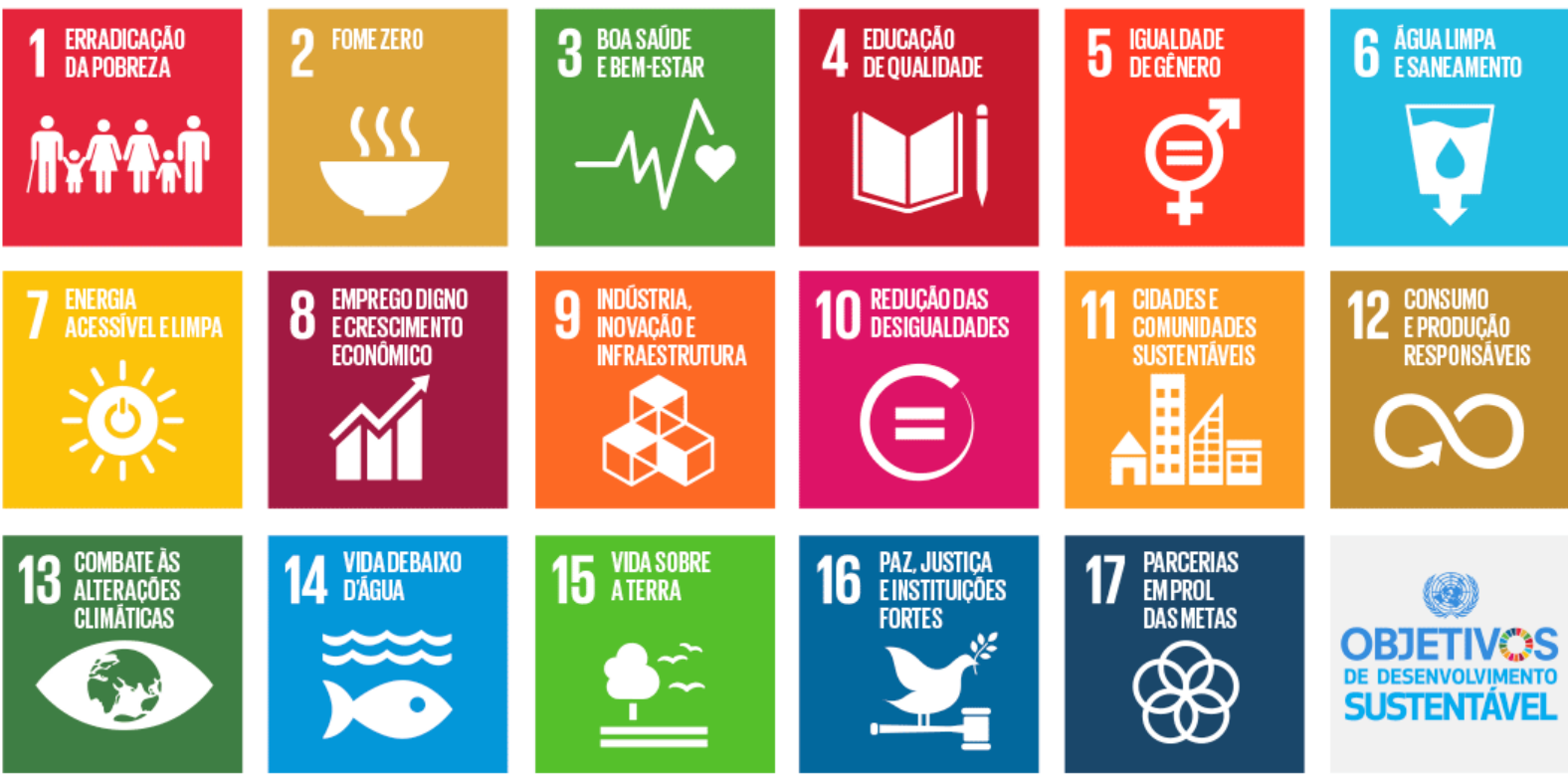

(6)

OBJETIVOS

DE DESENVOLVIMENTO SUSTENTÁVEL

Figura 1. Objetivos de Desenvolvimento Sustentável (ODS) (2015 a 2030). Adaptada da "Cúpula das Nações Unidas sobre o Desenvolvimento Sustentável," por ONU, 2009.

Pela Figura 1 é possível observar que os objetivos globais para o desenvolvimento sustentável abrangidos, assinados em setembro de 2015 por todos os líderes de países que compõem a ONU, contemplam metas para os 15 anos seguintes, ou seja, de 2015 a 2030 , e incluem acabar com a extrema pobreza, lutar contra desigualdade e injustiça e combater a mudança climática.

\subsection{GREEN LOGISTIC}

Bowersox et al. (2014) afirmam que a logística é um conceito em constante evolução, atrelado à busca de ganhos de competitividade e níveis de custos reduzidos. Eles destacam que esta era uma atividade considerada como função de apoio e que passou a ser considerada como um elemento estratégico nas empresas. Para Ballou (2006), a logística envolve todas as operações relacionadas com planejamento e controle de produção, como: movimentação de materiais, embalagem, armazenagem e expedição, distribuição física, transporte e sistemas de comunicação, que, realizadas de modo sincronizado, podem fazer com que as empresas agreguem valor aos serviços oferecidos aos clientes e, também, oportunizam um diferencial competitivo perante a concorrência.

Esse diferencial tratado por Ballou (2006) também é abordado por Faria e Costa (2012), que acrescentam que o objetivo da logística é fornecer ao cliente os níveis de serviço por ele requeridos mediante entrega realizada do produto certo, para o lugar, no momento, 
nas condições e pelos custos certos. Shapiro e Heskett (1985) citam mais dois itens, que são a quantidade e o cliente certos.

Guarnieri (2011) também corrobora Ballou (2006) ao descrever que o gerenciamento logístico deve ter o foco na integração das atividades da empresa e nas informações de todo o processo. Dessa forma, surge o conceito de logística integrada e a atuação em quatro áreas: a Logística de suprimentos ou de entrada (inbound); a Logística de produção ou interna; a Logística de distribuição ou de saída (outbound) e a Logística reversa. Faria e Costa (2012) destacam que foi na década de 1980 que a logística incorporou o foco na ampliação da visão global de empresa, com a cadeia de suprimentos e seus canais de distribuição, denominada Supply Chain Management (SCM). Nesse mesmo período, segundo Guarnieri (2011), foram evidenciados os aspectos e impactos causados pela atividade logística sobre a comunidade e a sustentabilidade ambiental, originando a Green Logistic e a Green Supply Chain Management (GSCM). Donato (2008) ressalta que a logística reversa se constitui parte da Green Logistic, pois dedica atenção ao retorno dos produtos, seja de embalagens, seja do próprio produto que deve ser descartado de forma ambientalmente apropriada ou mesmo reutilizado.

De acordo com Wang e Gupta (2012), foi também na década de 1980 que a Green Logistic nasceu, como vertente da logística, buscando atender às exigências governamentais sobre normas ambientais e novas diretrizes para as empresas. A logística, como salientam Bowersox et al. (2014), que até então tinha o foco na gestão econômica, passou a incorporar as exigências cada vez maiores de cuidados ambientais e sociais. Para os autores, a responsabilidade das empresas passou a ser considerada do começo ao fim do processo, reconhecendo que quem produz deve também se responsabilizar pelo destino final do produto gerado.

Fleury e Ribeiro (2001) salientam que a década de 1990 foi marcada pela terceirização, por meio dos operadores logísticos, também pelas vendas on-line, fornecendo atendimento ininterrupto, mais rápido e com preços mais acessíveis. Dias (2010) salienta que nos anos que se seguiram houve o desenvolvimento dos conceitos logísticos conhecidos até o momento, aliado à preocupação crescente com o meio ambiente. Sobre isso, o autor dá destaque para a Green Logistic e para as novas tecnologias que passaram a ser usadas no intercâmbio de informações entre os parceiros membros da cadeia logística, associados aos processos dos 3Rs (Reduzir, Reutilizar, Reciclar).

Ribeiro e Santos (2012) identificam que a Green Logistic é a parte da logística que prevê que as operações logísticas, de alguma forma, impactam o meio ambiente e que é necessária a criação de mecanismos para: conter o aumento de emissão de resíduos ao meio ambiente; evitar o armazenamento desprotegido de materiais; seu mau uso; e ausência de reaproveitamento. De acordo com os autores, é por meio da correta identificação dos 
eventos desfavoráveis que podem ser utilizados instrumentos de gestão para a mensuração dos impactos, buscando reduzir as agressões ao meio ambiente.

\subsection{PRÁTICAS DE SUSTENTABILIDADE VOLTADAS À GREEN LOGISTIC}

As práticas de sustentabilidade pesquisadas neste estudo estão relacionadas aos Green Logistic Costs, pois estes representam ações de sustentabilidade na concepção da Green Logistic, conforme depreendido do exposto por Dias (2010), Ferreira et al. (2011) e Srivastava (2007). A Green Logistic integra as atividades da cadeia de suprimentos com a gestão ambiental, visando melhorar ou preservar o meio ambiente, atender aos regulamentos ambientais e requisitos legais (Srivastava, 2007). Ainda, o autor reforça que essas ações não sacrificam a qualidade, o custo, a confiabilidade, o desempenho e a eficiência.

Da Green Logistic surgem custos específicos e, conforme Dias (2010), provocam ações para redução desses custos, como os processos dos 3 Rs citados na seção anterior. Ferreira et al. (2011) descrevem como exemplo de Green Logistic Costs o descarte seletivo e de forma adequada, o consumo de produtos com menos embalagens. Os autores salientam também que a sociedade, por meio de novas atitudes e exigências, pode contribuir para a redução desses custos.

Ribeiro e Santos (2012) descrevem algumas ações em que o governo pode atuar para contribuir na redução dos Green Logistic Costs: mediante ações de infraestrutura, disponibilizar vias de modais menos poluentes, como ferrovia, hidrovia e dutos ou transporte por cabotagem; por meio da melhoria das rodovias, proporcionando redução no consumo de combustíveis e manutenção de veículos; pela legislação e fiscalização, incluindo regras com diferentes ênfases:

a) de descarte de resíduos e coleta seletiva;

b) de exigência de retorno de resíduos;

c) de produção e manutenção de motores menos poluentes;

d) relacionadas à produção e ao consumo de combustíveis mais limpos e com menor emissão de poluentes pelas empresas;

e) criação de incentivos e financiamentos voltados para renovação de frotas, pesquisas de desenvolvimento e comercialização de novos combustíveis, desenvolvimento de novas tecnologias limpas. 
Já quanto às empresas, conforme López, Garcia, e Rodriguez (2007), elas podem atuar de forma direta e indireta para reduzir os Green Logistics Costs. Podem também atuar em mudanças na sua própria organização interna, como a criação de unidade organizacional responsável pela sustentabilidade ambiental, estabelecendo metas de redução de impactos ambientais e incentivos para atingi-las; e também a criação de auditorias internas, inventários periódicos de emissões e medições de pegada de carbono. $E$ todo esse processo sustentado pela realização de treinamentos internos de capacitação.

Tang e Zhao (2009) acrescentam que de forma indireta as empresas podem também tomar diversas iniciativas: efetuar mudanças no relacionamento com terceiros por meio da contratação de transportadoras com iniciativas ambientais; avaliar os prestadores de serviço e fornecedores também com critérios ambientais; utilizar fornecedores localizados em regiões mais próximas da empresa; e criar colaboração entre empresas e até com concorrentes para conquistar ganho de escala e uso conjunto de recursos.

Ubeda et al. (2011) também destacam iniciativas diretas que as empresas podem adotar com vistas a alcançar os benefícios pela Green Logistic: pela gestão logística, otimizar rotas e, pela revisão da rede logística, realizar a consolidação de cargas; melhor aproveitamento de veículos, viabilizando a redução no consumo de combustíveis; e pela utilização de combustível menos poluente ou do biocombustível, utilização de modais menos poluentes; pela redução ou reutilização e reciclagem de embalagens. Enfim, a realização da logística reversa viabiliza alcançar diversos benefícios na Green Logistic.

O Instituto de Logística e Supply Chain (ILOS, 2011) destaca formas proativas das empresas no âmbito da Green Logistic, particularmente com relação a investimento em ativos: renovação da frota, adaptações mecânicas e aerodinâmicas em veículos para redução de emissões; construções de centros de distribuição e fábricas seguindo diretrizes sustentáveis; e utilização de painéis solares, telhados verdes e paletes ecológicos, feitos de madeira de reflorestamento. Nota-se que o foco do ILOS se pauta em trocas de equipamentos por outros menos poluentes.

Com base nas narrativas dos vários autores pesquisados, percebe-se que a atuação da Green Logistic inclui diversas práticas de sustentabilidade, as quais podem ser fomentadas pelo governo, pelas empresas ou pessoas, e que elas evoluem gradativamente, principalmente atreladas aos acontecimentos desfavoráveis de natureza ambiental. Ressalta-se que as práticas elencadas não esgotam a literatura pertinente, mas exemplificam algumas ações de sustentabilidade voltadas para a Green Logistic. 


\section{METODOLOGIA DA PESQUISA}

Conforme o conceito proposto por Gil (2002), esta pesquisa identifica-se como bibliográfica quanto à sua finalidade, pois reúne estudos que têm como propósito explorar o conhecimento até então dado pela literatura disponível. Essa lacuna se evidenciou ao efetuar a busca na base de dados EBSCOHost e Portal de Periódicos Capes, em junho de 2015, pelas palavras-chave: práticas de sustentabilidade, Green Logistic e Green Logistics Costs. Ficou evidenciado que são escassos os estudos realizados sobre esses temas. Dado esse baixo número de estudos, torna-se relevante fomentar a pesquisa na temática.

Quanto ao seu objetivo, a pesquisa classifica-se como descritiva. Gil (2002) destaca que esse tipo de estudo tem por objetivo a descrição das características de determinada população ou grupo. Já com relação à abordagem do problema, a pesquisa classifica-se como qualitativa. De acordo com $\mathrm{Gil}$, ao empregar a pesquisa qualitativa, os pesquisadores estão mais preocupados com o processo social, buscam visualizar o contexto e almejam uma integração empática com o processo objeto de estudo que implique melhor compreensão do fenômeno.

Quanto aos procedimentos, a pesquisa é documental e multicaso. Vergara (2000) destaca que "investigação documental é a realizada em documentos conservados no interior de órgãos públicos, privados de qualquer natureza, ou com pessoas" (p. 48). Já o estudo multicaso, para Vergara "é o circunscrito a uma ou poucas unidades, tem caráter de profundidade e detalhamento, pode ou não ser realizada no campo" (p. 49). Dessa forma, nesta pesquisa os documentos pesquisados foram os Relatórios de Administração e os Relatórios de Sustentabilidade publicados nos portais eletrônicos das empresas analisadas, referentes aos anos de 2014 a 2018; constitui-se em um estudo multicaso por abranger três empresas atuantes no Brasil, no segmento de cosméticos.

A escolha de empresas do segmento de cosméticos perpassou pela relevância do setor, pois conforme a ABIHPEC (2018), o mercado nacional é apontado como o quarto maior do mundo nesse segmento. Para a operacionalização da pesquisa, procedeu-se à identificação das empresas, objeto do estudo. A seleção ocorreu por informações divulgadas na mídia eletrônica, como: Revista Exame ("As 5 maiores", 2016), mostrando as cinco maiores empresas de beleza no Brasil; e Revista Exame ("As melhores", 2017), com a informação das 500 maiores e melhores empresas de 2016. Destaca-se que, em ambas as publicações, a Avon Cosméticos, o Boticário e a Natura representam as três empresas com maior faturamento de cosméticos do Brasil, com base no ano de 2016.

Os relatórios de sustentabilidade foram coletados no período de agosto a setembro de 2019. A busca ocorreu primeiro no Google, por "relatório de sustentabilidade" acrescido do nome da empresa, que deu acesso aos portais institucionais das três empresas. Quanto 
à empresa Avon, infelizmente os relatórios da administração referentes ao período de 2015 a 2018 não estão disponíveis. Envidaram-se todos os esforços na busca de tais relatórios, compreendendo contato com a empresa pelo sistema 0800 e diversos revendedores, diretamente com a fábrica instalada em São Paulo. Por último, tentou-se contato com o controller via redes sociais, já que não se conseguiu o contato com o setor de relações institucionais. Todas as tentativas foram em vão. Nesse sentido, foi analisado apenas o relatório do ano de 2014.

Os documentos na sequência passaram pela técnica da análise de conteúdo, conforme os pressupostos de Bardin (1977). Para identificar as práticas de sustentabilidade voltadas à Green Logistic foram utilizadas palavras-chave e sinônimos identificados na literatura descrita na segunda seção deste artigo, a saber: descarte, embalagem, reduzir, reciclar, recuperar, reaproveitar, redefinir, transporte, preservar, desperdício e ISO. Apresentam-se a seguir os resultados e discussões pertinentes à coleta, sistematização dos dados e discussão dos resultados.

\section{APRESENTAÇÃO E ANÁLISE DOS DADOS E DISCUSSÃO DOS RESULTADOS}

Após a coleta e sistematização dos dados, realizadas por meio de análise de conteúdo dos Relatórios de Administração, essencialmente dos Relatórios de Sustentabilidade das empresas Avon Cosméticos, o Boticário e Natura, foram identificadas as Práticas de Sustentabilidade voltadas para a Green Logistic nessas empresas, descritas a seguir.

\subsection{APRESENAÇÃO E ANÁLISE DOS DADOS}

\subsubsection{Avon Cosméticos}

A Avon foi fundada nos Estados Unidos da América - EUA. Em 1895 instalou sua base industrial na Cidade de Suffern, EUA; em 1896, lançou seu primeiro folheto. Inovou ao utilizar o modelo de distribuição de produtos por meio de revendedoras autônomas. Em 1902, já tinha 10 mil revendedoras. Em 1920, a empresa se posicionou em diversas categorias, como sabonetes, produtos para banho, higiene bucal, limpeza doméstica e aromatizantes. Em 1970, inaugurou uma fábrica no Brasil.

Em 2003 no Brasil é criado o Instituto Avon e, em 2010, é lançada a campanha "Viva - Amanhã mais Verde", com o objetivo de promover a restauração de áreas desflorestadas. A empresa busca continuamente reduzir o impacto ambiental por meio de uma rede mundial 
de gestão ambiental, associada em várias disciplinas, apoiando políticas globais, processos e objetivos comuns. A Tabela 1 descreve as práticas de sustentabilidade identificadas na empresa Avon Cosméticos, voltadas à Green Logistic:

Tabela 1

Práticas de sustentabilidade voltadas à Green Logistic da empresa Avon Cosméticos

\begin{tabular}{lll}
\hline Palavras-chave & \multicolumn{1}{c}{ Aporte teórico } & \multicolumn{1}{c}{ Ações da Avon Cosméticos } \\
\hline & $\begin{array}{l}\text { Ferreira et al. } \\
\text { (2011) e ISO }\end{array}$ & \\
Redefinir & $\begin{array}{l}\text { 14000-Environ- } \\
\text { mental Manage- } \\
\text { ment (2009) }\end{array}$ & \\
& mais. & \\
\hline
\end{tabular}

\begin{tabular}{ll}
$\begin{array}{l}\text { Gases de Efeito } \\
\text { Estufa (GEEs) }\end{array}$ & $\begin{array}{l}\text { Ribeiro e Santos } \\
(2012)\end{array}$ \\
\hline Recuperar & $\begin{array}{l}\text { ISO 14000-Envi- } \\
\text { ronmental Mana- } \\
\text { gement (2009) }\end{array}$ \\
\hline
\end{tabular}

1994: Tornou-se uma das primeiras empresas de beleza a priorizar o foco na redução de Gases de Efeito Estufa (GEEs) nas suas operações.

A empresa aderiu ao programa Green Lights da Agência de Proteção Ambiental dos EUA, com iluminação energeticamente eficiente. 2010: Plantio de dois milhões de árvores na Mata Atlântica Brasileira.

2010: Iniciou a operar o maior Centro de Distribuição-CD da empresa no Brasil e foi construído com a certificação verde Leed Gold.

Práticas de construção sustentável

$\operatorname{ILOS}(2011)$
Avon Green Building Promise: concepção, construção e reformas para instalações com economia de energia, eficiência da água, redução de emissão de carbono e gestão dos recursos naturais, com certificação Green Building Rating System e LEED.

\begin{tabular}{|c|c|c|}
\hline Reduzir & $\begin{array}{l}\text { Agenda } 21- \\
\text { Ministério do Meio } \\
\text { Ambiente (MMA, } \\
\text { 2015), Dias (2008) } \\
\text { e Donato (2008) }\end{array}$ & $\begin{array}{l}\text { Avalia continuamente formas de reduzir o impacto ambiental nas } \\
\text { operações e na fabricação dos produtos. }\end{array}$ \\
\hline \multirow[b]{2}{*}{$\begin{array}{l}\text { Pegada de car- } \\
\text { bono }\end{array}$} & \multirow{2}{*}{$\begin{array}{l}\text { Agenda 21-MMA } \\
\text { (2015), Dias (2010), } \\
\text { ISO 14000-Envi- } \\
\text { ronmental Mana- } \\
\text { gement (2009) e } \\
\text { Ribeiro e Santos } \\
\text { (2012) }\end{array}$} & $\begin{array}{l}\text { Utiliza energias renováveis para reduzir a pegada de carbono. } \\
\text { objetivo é atingir emissões zero, usando } 100 \% \text { de energia limpa. }\end{array}$ \\
\hline & & 2013: Reduziu 28,7\% em relação a 2005. \\
\hline $\begin{array}{l}\text { Modais de } \\
\text { transporte menos } \\
\text { poluentes }\end{array}$ & $\begin{array}{l}\text { Ribeiro e Santos } \\
\text { (2012) }\end{array}$ & $\begin{array}{l}\text { Durante a última década, foram introduzidas práticas de transporte } \\
\text { marítimo eficazes para reduzir os impactos ambientais de distribui- } \\
\text { ção dos produtos. }\end{array}$ \\
\hline \multirow[b]{2}{*}{$\begin{array}{l}\text { Relacionamento } \\
\text { com terceiros }\end{array}$} & \multirow[b]{2}{*}{$\begin{array}{l}\text { Tang e Zhao } \\
\text { (2009) }\end{array}$} & $\begin{array}{l}\text { Firmou parceria com transportadoras e operadores logísticos, apro- } \\
\text { veitando as melhores opções e especialidades. }\end{array}$ \\
\hline & & $\begin{array}{l}\text { Fez parcerias com a cadeia de fornecimento para minimizar o } \\
\text { consumo de combustível e buscar alternativas no abastecimento de } \\
\text { combustível com menos impactos ambientais. }\end{array}$ \\
\hline $\begin{array}{l}\text { Redução de im- } \\
\text { pactos ambientais } \\
\text { na distribuição } \\
\text { dos produtos }\end{array}$ & $\begin{array}{l}\text { ILOS (2011), } \\
\text { Ribeiro e Santos } \\
\text { (2012) e Ubeda et } \\
\text { al. (2011) }\end{array}$ & $\begin{array}{l}\text { Distribuição regional por meio de centros de distribuição; melhorias } \\
\text { nas opções de envio, por exemplo: redução de embalagens, desen- } \\
\text { volvimento de planos de otimização que reduzem quilometragem, } \\
\text { combustível e tempo gasto relativo a transferências. }\end{array}$ \\
\hline
\end{tabular}

As práticas evidenciadas pela empresa Avon Cosméticos (Tabela 1) foram elencadas em oito categorias e declararam 12 ações realizadas no período analisado. Essas ações estão em consonância com o recomendado pela literatura, conforme se observa na segunda 
coluna da Tabela 1 o aporte teórico citado que recomenda tais práticas de sustentabilidade. Algumas são voltadas diretamente à Green Logistic, como redução de gases de efeito estufa; uso de outros modais de transporte, como o transporte marítimo; parcerias com as transportadoras; cadeia de fornecimento e operadores logísticos; redução de embalagens; e otimização na distribuição dos produtos. As demais práticas citadas são indiretamente relacionadas à Green Logistic. Até o momento não é possível afirmar que estas não se relacionam, pois os aspectos e impactos ambientais decorrentes da atividade logística são muito amplos e abrangentes, como destacado por Dias (2010), Donato (2008), Guarnieri (2011), Srivastava (2007) e Wang e Gupta (2012).

\subsection{2 o Boticário}

Em 1977, Miguel Krisger abriu uma farmácia de manipulação em Curitiba, PR, investindo na elaboração de cosméticos naturais, dando início à empresa o Boticário. Em 1979 foi inaugurada a primeira loja e, em 1980, aberta a primeira franquia. Em 1982 foi construída a primeira fábrica e, em 1986, inaugurada a primeira loja fora do País, em Lisboa, Portugal. Em 1990, a empresa criou a Fundação "O Boticário de Proteção à Natureza" e, em 1994 adquiriu a Reserva Natural Salto Morato, PR. Em 2008 entrou em atividade o laboratório de Biologia Molecular, que é o Núcleo de Estudos Biológicos e Alternativos da empresa. Em 2010 houve a criação do Grupo Boticário e em 2013 a inauguração do Centro de Pesquisa e Desenvolvimento, em São José dos Pinhais, PR. Em 2014 foi inaugurada a nova fábrica de perfumaria e cosméticos na Bahia. A empresa possui as marcas Eudora, Quem Disse Berenice, o Boticário e The Beauty Box e é 100\% brasileira. A Tabela 2 descreve as práticas de sustentabilidade identificadas na empresa o Boticário, voltadas à Green Logistic: 
Tabela 2

Práticas de sustentabilidade voltadas à Green Logistic da empresa o Boticário

\begin{tabular}{|c|c|c|}
\hline$\underset{\Xi}{ \pm}$ & 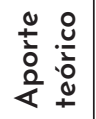 & Ações da empresa o Boticário \\
\hline \multirow{13}{*}{ 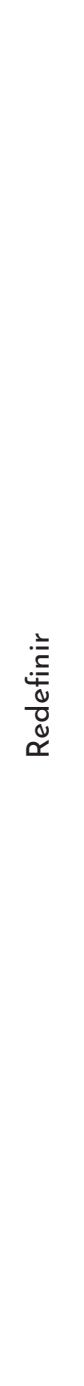 } & \multirow{13}{*}{ 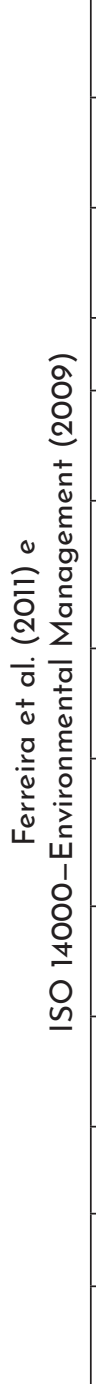 } & $\begin{array}{l}\text { Desde 2012: Tem concentrado esforços de melhoria nas matérias-primas e embalagens; na ecoe- } \\
\text { ficiência; nos canais de venda. }\end{array}$ \\
\hline & & $\begin{array}{l}15 \text { Projetos implantados para a redução de embalagem sem perda de qualidade, diminuindo } \\
14 \% \text { a quantidade de material utilizado e contribuindo para a redução no impacto ambiental. }\end{array}$ \\
\hline & & $\begin{array}{l}\text { Foram implantadas quatro novas tecnologias de embalagem, sendo uma de fonte renovável e } \\
\text { as demais usam material pós-consumo. }\end{array}$ \\
\hline & & Desenvolveu estudos para avaliar a reciclabilidade das embalagens. \\
\hline & & $\begin{array}{l}\text { 2014: Procurou conhecer o ciclo de vida dos produtos, identificando possíveis impactos desde a } \\
\text { etapa de obtenção das matérias-primas até o descarte da embalagem. }\end{array}$ \\
\hline & & $\begin{array}{l}\text { Foram desenvolvidos estudos e metodologias de avaliação de ecotoxicidade para as maté- } \\
\text { rias-primas, com o objetivo de medir o impacto ambiental e o uso de ingredientes de produtos } \\
\text { enxaguáveis. }\end{array}$ \\
\hline & & $\begin{array}{l}\text { 2016: Houve substituição nos displays do acrílico das gavetas, corrediças e puxadores por MDF } \\
\text { cru, melhorando a reciclabilidade e o impacto ambiental. }\end{array}$ \\
\hline & & $\begin{array}{l}\text { 2015: Reciclou, reutilizou ou fez coprocessamento de } 96 \% \text { dos resíduos gerados em suas instala- } \\
\text { ções. Utilizou água de reúso e da chuva em duas de suas plantas industriais, e efetivou trata- } \\
\text { mento próprio de efluente em uma de suas unidades industriais. }\end{array}$ \\
\hline & & $\begin{array}{l}\text { 2015: O Centro de Pesquisa e Desenvolvimento mapeou, testou e aprovou } 17 \text { novas matérias-pri- } \\
\text { mas e dois materiais de embalagens que oferecem ganhos em sustentabilidade. }\end{array}$ \\
\hline & & $\begin{array}{l}\text { 2016: Mudança no design de embalagens com economia de plástico de } 10 \% \text {, o que equivale a } \\
90 \text { toneladas ao ano; redução de } 55 \text { toneladas de vidro ao ano. }\end{array}$ \\
\hline & & 2016: 94\% dos resíduos sólidos gerados em duas plantas industriais são destinados à reciclagem. \\
\hline & & 2016: Ampliação da utilização da água de reúso para torres de resfriamento. \\
\hline & & $\begin{array}{l}\text { 2016: Uso de plástico vegetal em embalagens, produzido a partir da cana de açúcar, fortalecen- } \\
\text { do o processo de ecoeficiência. }\end{array}$ \\
\hline \multirow{3}{*}{ 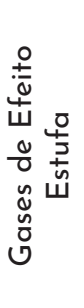 } & \multirow{3}{*}{ 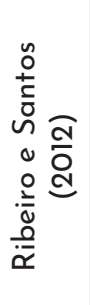 } & $\begin{array}{l}\text { 2014: Foi executado um piloto para a redução da emissão de gases de efeito estufa no transpor- } \\
\text { te de distribuição. }\end{array}$ \\
\hline & & $\begin{array}{l}\text { 2015: Mudança no processo produtivo para menor temperatura de aquecimento que levou à } \\
\text { maior eficiência energética e menos emissão de gases causadores do efeito estufa. }\end{array}$ \\
\hline & & $\begin{array}{l}\text { 2016: As novas práticas de logística implicaram redução de } 19,6 \% \text { de gases de efeito estufa com } \\
\text { relação ao ano anterior. }\end{array}$ \\
\hline
\end{tabular}




\begin{tabular}{|c|c|c|}
\hline$\underset{\Xi}{\underline{\varepsilon}}$ & 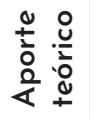 & Ações da empresa o Boticário \\
\hline \multirow{5}{*}{ 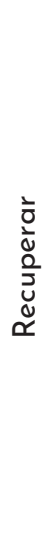 } & \multirow{5}{*}{ 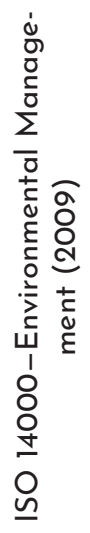 } & 2007: Criou a Reserva Natural da Serra do Tombador, em GO, com 8.900 hectares de Cerrado. \\
\hline & & $\begin{array}{l}\text { 2015: Pequenas áreas de recuperação na Reserva Natural Salto Morato, PR, e Reserva Natural } \\
\text { Serra do Tombador, GO, que são áreas protegidas pela Fundação Grupo Boticário de Proteção } \\
\text { à Natureza. }\end{array}$ \\
\hline & & 2016: 1.510 iniciativas apoiadas e 496 Unidades de Conservação beneficiadas. \\
\hline & & $\begin{array}{l}\text { 2017: Influência em políticas públicas para seis novas unidades de conservação criadas, nos Es- } \\
\text { tados do Piauí, Bahia e Minas Gerais, e três unidades de conservação ampliadas, uma em Goiás } \\
\text { e duas no Paraná. }\end{array}$ \\
\hline & & $\begin{array}{l}\text { 2017: Projeto Araucária +, resultado da parceria com a Fundação CERTI, modelo de negócio } \\
\text { para conservação integrada que alia a produção sustentável de pinhão e erva-mate. }\end{array}$ \\
\hline \multirow{5}{*}{ 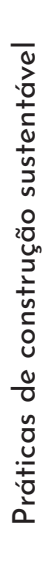 } & \multirow{5}{*}{$\begin{array}{l}\widehat{\overline{\bar{O}}} \\
\text { } \\
\text { O } \\
\stackrel{=}{=}\end{array}$} & 2008: Construiu um novo prédio na planta industrial dentro do conceito Green Building. \\
\hline & & $\begin{array}{l}\text { 2015: A empresa instalou os primeiros dômus prismáticos no centro de distribuição, passagem } \\
\text { de luz natural sem aquecer o ambiente, que repercutiu em redução do uso de energia e de } \\
\text { resíduos. }\end{array}$ \\
\hline & & $\begin{array}{l}\text { 2015: Inaugurou a primeira fábrica brasileira e o primeiro centro de distribuição a receberem a } \\
\text { certificação Leadership in Energy and Enviromental Design (LEED). A empresa teve a primeira } \\
\text { loja com essa certificação também. }\end{array}$ \\
\hline & & $\begin{array}{l}\text { 2015: } 80 \% \text { dos pisos das lojas são de materiais reciclados, uso de madeiras com certificação } \\
\text { florestal, reutilização de mobiliários. Estudo técnico de otimização de energia na iluminação das } \\
\text { lojas prevê redução de } 26 \% \text { da conta de luz. }\end{array}$ \\
\hline & & 2016: Certificação LEED para pontos de venda. \\
\hline \multirow{6}{*}{ 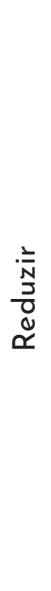 } & \multirow{6}{*}{ 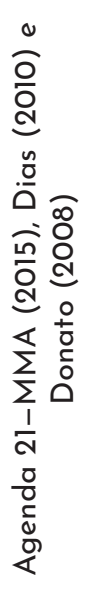 } & 1999: Conquistou o prêmio Top Social-ADVB para as ações de "reduzir, reciclar, reutilizar". \\
\hline & & $\begin{array}{l}\text { Em } 2014 \text { foi realizado um repacking de uma fragrância, com redução de } 25 \% \text { no volume de } \\
\text { resíduos gerados na produção. }\end{array}$ \\
\hline & & $\begin{array}{l}\text { 2015: Repacking de produtos clássicos chegaram às lojas com redução no impacto ambiental e } \\
\text { expansão do Programa Reciclagem de Embalagens para todas as unidades de negócio. }\end{array}$ \\
\hline & & $\begin{array}{l}\text { 2015: Produção ecoeficiente com redução de } 71 \% \text { do tempo de fabricação, } 70 \% \text { do consumo de } \\
\text { energia elétrica; } 15 \% \text { do custo de transformação e } 10 \% \text { do custo de matérias-primas. }\end{array}$ \\
\hline & & $\begin{array}{l}\text { Desde } 2011 \text { utiliza no processo produtivo tensoativos com três matérias-primas em uma só, que } \\
\text { reduzem a quantidade de reagentes para verificações de qualidade. }\end{array}$ \\
\hline & & $\begin{array}{l}\text { 2015: Redução de tamanho das caixas e sacolas de presente, gerando redução de } 20 \% \text { do im- } \\
\text { pacto ambiental. }\end{array}$ \\
\hline
\end{tabular}




\begin{tabular}{|c|c|c|}
\hline $\begin{array}{l}\xi \\
\stackrel{\xi}{u} \\
\pm\end{array}$ & 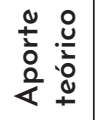 & Ações da empresa o Boticário \\
\hline \multirow{9}{*}{ 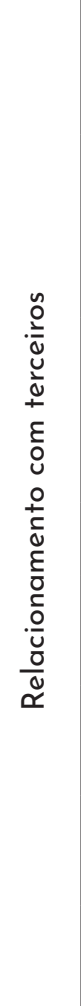 } & \multirow{9}{*}{ 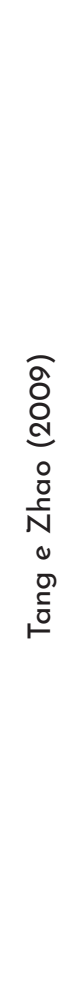 } & $\begin{array}{l}\text { Desde } 2010 \text { possui um índice para mensurar seu desempenho sustentável, dividido em: "transpa- } \\
\text { rência; inserção da sustentabilidade nos processos; capilaridade da atuação e engajamento da } \\
\text { cadeia de valor; e reputação/expressão". }\end{array}$ \\
\hline & & Ações de sustentabilidade com os fornecedores, para melhorar processos e produtos. \\
\hline & & $\begin{array}{l}\text { Em uma avaliação da cadeia produtiva, foram observados componentes significativos para as } \\
\text { embalagens utilizadas. }\end{array}$ \\
\hline & & $\begin{array}{l}\text { Desde } 2012 \text { são realizadas avaliações, monitoramentos, visitas de sustentabilidade, oficinas e } \\
\text { campanhas de comunicação com as transportadoras e operadores logísticos, procurando iden- } \\
\text { tificar oportunidades de redução de consumo, tempo para a emissão de gases causadores do } \\
\text { efeito estufa. }\end{array}$ \\
\hline & & Incentivo à inserção de práticas sustentáveis em toda a cadeia de valor. \\
\hline & & $\begin{array}{l}\text { Desde } 2005 \text { existe a Gestão de Sustentabilidade para Fornecedores, que desenvolve e constrói } \\
\text { uma atuação de parceria com todos os fornecedores. }\end{array}$ \\
\hline & & $\begin{array}{l}\text { 2015: Contribuiu com transportadoras parceiras e com a profissionalização de cinco empresas } \\
\text { de reciclagem. }\end{array}$ \\
\hline & & $\begin{array}{l}\text { 2015: Estruturação do programa de parceria em ecoeficiência com os fornecedores-alvo da } \\
\text { cadeia de valor. }\end{array}$ \\
\hline & & $\begin{array}{l}\text { 2016: Programa de parceria em ecoeficiência com fornecedores, redução de } 9.098 \text { megawatt e } \\
\text { de } 41.000 \text { de } \mathrm{CO}^{2} / \text { ano. }\end{array}$ \\
\hline \multirow{4}{*}{ 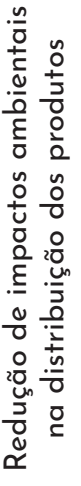 } & \multirow{4}{*}{ 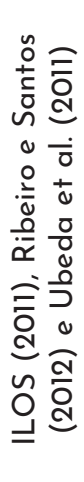 } & $\begin{array}{l}\text { Os itens necessários para montagem da embalagem de um dos produtos mais vendidos do } \\
\text { portfólio da marca foram reduzidos de oito para cinco, resultando em otimização logística. }\end{array}$ \\
\hline & & $\begin{array}{l}\text { Também diminuiu a quantidade de caixas de papelão, bandejas e sacos plásticos necessários } \\
\text { para o transporte e armazenamento do item. }\end{array}$ \\
\hline & & $\begin{array}{l}\text { 2014: Instalaram kit bicombustível em caminhões, que permite o abastecimento do veículo com } \\
50 \% \text { de gás natural veicular e } 50 \% \text { de diesel; o projeto propõe uma adaptação em caráter } \\
\text { imediato da frota. }\end{array}$ \\
\hline & & $\begin{array}{l}\text { 2016: Ampliação do uso do kit biocombustível, otimização de rotas e percursos, reaproveitamen- } \\
\text { to de } 45 \% \text { de espaço vertical nas caçambas. }\end{array}$ \\
\hline \multirow{5}{*}{ 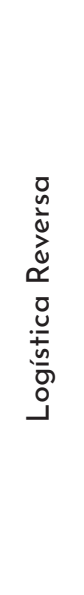 } & \multirow{5}{*}{ 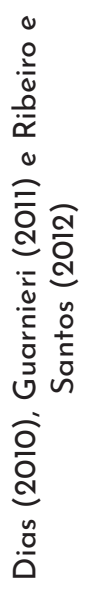 } & $\begin{array}{l}\text { As embalagens pós-consumo devolvidas em qualquer uma das lojas e centrais de serviço são } \\
\text { destinadas à reciclagem por meio de cooperativas de catadores e empresas gerenciadoras de } \\
\text { resíduos homologadas. }\end{array}$ \\
\hline & & $\begin{array}{l}\text { A logística reversa no grupo tornou-se efetiva, representando aumento de } 30 \% \text { no recolhimento } \\
\text { do último trimestre do ano de } 2014 \text {. }\end{array}$ \\
\hline & & $\begin{array}{l}\text { Os incentivos para que o consumidor devolva as embalagens pós-consumo somaram grande } \\
\text { volume de materiais coletados e enviados para a reciclagem. }\end{array}$ \\
\hline & & $\begin{array}{l}\text { 2015: A campanha do dia do beijo arrecadou } 17.800 \text { batons, que foram destinados, por meio } \\
\text { da logística reversa, à parte pigmentada para combustível de fornos da indústria cimenteira e } \\
\text { para reciclagem à parte plástica. }\end{array}$ \\
\hline & & $\begin{array}{l}\text { 2016: Campanha o dia da troca, com } 15 \% \text { de desconto em qualquer item a consumidores que } \\
\text { entregassem uma embalagem vazia. }\end{array}$ \\
\hline
\end{tabular}


As práticas evidenciadas pela empresa o Boticário (Tabela 2), foram descritas em oito categorias de análise e nestas foram declaradas 50 ações realizadas no período de análise. A maioria destas ações (22) foram evidenciadas no ano de 2014; já em 2015 foram 15 ações; e em 201611 ações. O foco da sustentabilidade da empresa o Boticário no ano de 2017 voltou-se para a conservação da natureza, para as áreas protegidas, para as espécies e ecossistemas, para a economia da biodiversidade e para o engajamento da sociedade. No ano de 2018 houve continuidade das ações do ano anterior e incremento no incentivo à pesquisa científica de espécies e ecossistemas, na geração e propagação de conhecimento, na articulação e influência em setores estratégicos e políticas públicas.

Dessa forma, destaca-se a mudança de rumos efetivada pela empresa, refletida pela evidenciação nos relatórios de sustentabilidade no período analisado, sendo que nos três primeiros anos o foco era voltado para instalações, produto, processo produtivo e distribuição, e nos últimos dois anos voltou-se para as pessoas.

Nota-se que, com relação à empresa Avon, a empresa o Boticário se antecipou na construção de planta industrial com o conceito de Green Building. Outra ação que merece destaque é a logística reversa, que contribui na prática da Green Logistic (Donato, 2008). Entre as categorias listadas, as voltadas diretamente à Green Logistic foram: redefinir, redução de gases de efeito estufa, redução de impactos ambientais na distribuição dos produtos, relacionamento com terceiros e logística reversa, com base nos pressupostos de Dias (2010), Ferreira et al. (2011), López et al. (2007), Ribeiro e Santos (2012), Tang e Zhao (2009) e Ubeda et al. (2011).

\subsubsection{Natura}

A Natura foi fundada em 1969, em São Paulo. Em 1974 optou pela venda direta de seus produtos. A visão de sustentabilidade, lançada em 2014, impulsionou as ambições futuras da Natura. Alinhada à estratégia de negócio, essa visão teve como objetivo gerar impacto positivo em todas as dimensões das atividades da empresa, o que significa ir além do paradigma de apenas reduzir e mitigar impactos, ajudando o meio ambiente e a sociedade a se tornarem melhores. Com esse propósito, foram estabelecidas diretrizes para orientar a evolução até 2050 e com metas que devem ser alcançadas até 2020. Essas metas foram estruturadas em três pilares: Marcas e Produtos, Nossa Rede, Gestão e Organização. A administração integrada deve estar incorporada à cultura organizacional. A empresa possui as marcas: Natura, Aēsop e The Body Shop. Possui instalações em cinco países e atua em 72. A Tabela 3 descreve as práticas de sustentabilidade identificadas na empresa Natura, voltadas à Green Logistic. 
Tabela 3

Práticas de sustentabilidade voltadas à Green Logistic da empresa Natura

\begin{tabular}{|c|c|c|}
\hline 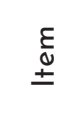 & 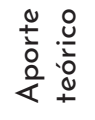 & Ações da Natura \\
\hline \multirow{13}{*}{ 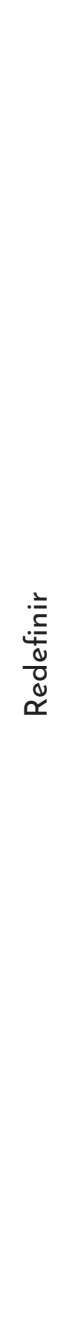 } & \multirow{13}{*}{ 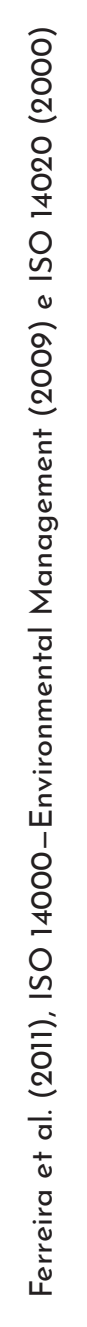 } & 1983: Foi a primeira empresa de cosméticos a oferecer refil de produtos. \\
\hline & & 2006: Passou a realizar testes com material sintético, encerrando as pesquisas com animais. \\
\hline & & 2013: Criou a linha SOU, que reduz o impacto ambiental da matéria-prima pós-consumo. \\
\hline & & $\begin{array}{l}\text { 2014: Valorização da sociobiodiversidade: promoção de negócios sustentáveis por meio da } \\
\text { utilização de produtos e serviços provenientes principalmente da região Pan-Amazônica. }\end{array}$ \\
\hline & & $\begin{array}{l}\text { 2014: Transparência e origem dos produtos: ampliação da visibilidade sobre as práticas } \\
\text { empresariais e a origem dos produtos. }\end{array}$ \\
\hline & & $\begin{array}{l}\text { 2015: } 83 \% \text { dos produtos é de origem vegetal, fato que amplia a preservação ambiental; } \\
\text { grande parte das embalagens tem grande potencial de reciclabilidade e uso de refis é mais } \\
\text { incentivado a cada ano; a empresa lançou linha de produtos com } 50 \% \text { de PET verde e } 50 \% \\
\text { reciclado, e } 40 \% \text { do cartucho com papel reciclado. Ao total utilizou (apenas) } 2,9 \% \text { de mate- } \\
\text { rial reciclado pós-consumo em suas embalagens. }\end{array}$ \\
\hline & & $\begin{array}{l}\text { 2016: Uso de álcool orgânico em } 100 \% \text { da perfumaria, produzido sem agrotóxicos, adubos } \\
\text { químicos ou uso de queimadas, regenerando a vida em } 20 \text { mil hectares de matas. }\end{array}$ \\
\hline & & $\begin{array}{l}\text { 2016: } 20 \% \text { das embalagens são ecoeficientes, uso de } 597 \text { mil garrafas de } 1 \text { litro de vidro } \\
\text { reciclado nas embalagens. Ao total utilizou } 4,3 \% \text { de material reciclado pós-consumo em suas } \\
\text { embalagens. }\end{array}$ \\
\hline & & $\begin{array}{l}\text { 2017: A equipe de embalagens fez redução de peso em alguns produtos de frascos de } 200 \\
\mathrm{~mL} \text { e uso no e-commerce de papelão } 100 \% \text { reciclável, sem uso de fita ou cola. }\end{array}$ \\
\hline & & 2018: $22 \%$ das embalagens são ecoeficientes. \\
\hline & & 2018: $33 \%$ da água foi reciclada e reutilizada. \\
\hline & & $\begin{array}{l}\text { 2018: Criou o Índice de Visão de Sustentabilidade, com indicadores qualitativos e quantitati- } \\
\text { vos com compromissos para } 2030 .\end{array}$ \\
\hline & & $\begin{array}{l}\text { 2018: Recebeu a certificação internacional da União para o BioComércio Ético para os pro- } \\
\text { dutos de uma de suas linhas, que atesta a sustentabilidade da cadeia de fornecimento. }\end{array}$ \\
\hline \multirow{3}{*}{ 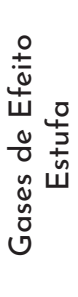 } & \multirow{3}{*}{ 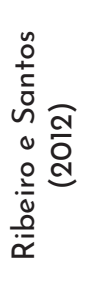 } & 2013: Reduziu um terço das emissões de gases de efeito estufa. \\
\hline & & $\begin{array}{l}\text { 2014: Redução das emissões de gases de efeito estufa em toda a cadeia e neutralização por } \\
\text { meio de projetos que incluam benefícios sociais. }\end{array}$ \\
\hline & & $\begin{array}{l}\text { 2016: Redução de } 0,5 \% \text { nas emissões relativas de GEE, que perpassou a escolha dos insumos } \\
\text { para produção, manufatura, transporte e demais processos com vistas a abranger toda a } \\
\text { cadeia produtiva. }\end{array}$ \\
\hline
\end{tabular}




\begin{tabular}{|c|c|c|}
\hline$\stackrel{\varepsilon}{\Phi}$ & 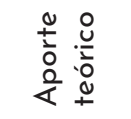 & Ações da Natura \\
\hline \multirow{6}{*}{ 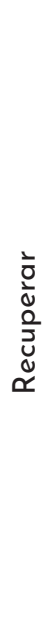 } & \multirow{6}{*}{ 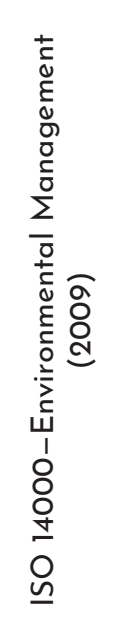 } & $\begin{array}{l}\text { 2011: Lançou o Programa Amazônia, para tornar a região um polo de inovação, tecnologia } \\
\text { sustentabilidade. }\end{array}$ \\
\hline & & $\begin{array}{l}\text { 2014: Foi inaugurado o Ecoparque em Benevides, PA, um complexo industrial que preten- } \\
\text { de gerar negócios sustentáveis a partir da sociobiodiversidade amazônica e impulsionar o } \\
\text { empreendedorismo local. }\end{array}$ \\
\hline & & $\begin{array}{l}\text { 2015: Consolidação de arranjos de desenvolvimento territorial do Médio Juruá, AM, Baixo } \\
\text { Tocantins, PA e Transamazônica, PA, com avanços nas áreas de educação, infraestrutura, } \\
\text { saneamento básico e cadeias produtivas das regiões. }\end{array}$ \\
\hline & & $\begin{array}{l}\text { 2016: Estimulou a geração de negócios sustentáveis como alternativa econômica para a } \\
\text { região da Amazônia e ajudou a conservar } 256.798 \text { hectares de floresta em pé. }\end{array}$ \\
\hline & & $\begin{array}{l}\text { 2016: Apoiou } 13 \text { projetos de restauro florestal e } 5 \text { projetos de conservação florestal, com } \\
\text { vistas à compensação de Carbono. }\end{array}$ \\
\hline & & 2017: 261.000 hectares de florestas conservadas. \\
\hline \multirow{5}{*}{ 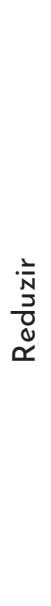 } & \multirow{5}{*}{ 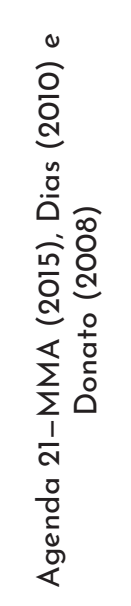 } & $\begin{array}{l}\text { 2014: Gestão de resíduos-desenvolvimento de embalagens de menor impacto ambiental e } \\
\text { que promovam o consumo consciente. }\end{array}$ \\
\hline & & $\begin{array}{l}\text { Busca reduzir gradativamente a geração de resíduos em toda a cadeia de valor e busca o } \\
\text { rejeito zero nas plantas próprias e no sistema de distribuição, por meio de um planejamento } \\
\text { logístico eficiente e soluções inovadoras para comercialização, acondicionamento e entrega } \\
\text { de produtos. }\end{array}$ \\
\hline & & $\begin{array}{l}\text { Com base neste inventário, a empresa estruturou uma estratégia que contempla os requisi- } \\
\text { tos da Política Nacional de Resíduos Sólidos brasileira, visando reduzir a geração de resídu- } \\
\text { os e rejeitos na cadeia e ampliar o uso de materiais reciclados pós-consumo nos processos e } \\
\text { produtos. }\end{array}$ \\
\hline & & $\begin{array}{l}\text { 2015: Iniciou um projeto com cinco cooperativas que coletou } 306 \text { toneladas de resíduos para } \\
\text { reciclagem. }\end{array}$ \\
\hline & & 2018: Reduziu $11 \%$ a geração de resíduos. \\
\hline \multirow{3}{*}{ 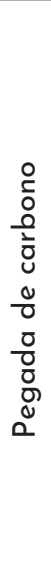 } & \multirow{3}{*}{ 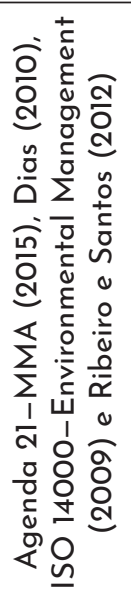 } & $\begin{array}{l}\text { 2007: Lançou o Programa Carbono Neutro, comprometendo-se com metas ousadas de } \\
\text { redução das emissões } \mathrm{CO}_{2} \text { em toda a cadeia produtiva, com três dimensões: mensuração, } \\
\text { redução e compensação. }\end{array}$ \\
\hline & & $\begin{array}{l}\text { 2015: Compensa todas as emissões de } \mathrm{CO}_{2^{\prime}} \text { por meio do Programa Carbono Neutro, com } \\
\text { aquisição de créditos de carbono e uso de ativos da biodiversidade. }\end{array}$ \\
\hline & & $\begin{array}{l}\text { 2018: Redução de } 2 \% \text { de emissão de Carbono com relação ao ano anterior, ao total deixou } \\
\text { de emitir } 9.127 \text { toneladas de } \mathrm{CO}_{2} \text {. }\end{array}$ \\
\hline
\end{tabular}




\begin{tabular}{|c|c|c|}
\hline$\underset{\Phi}{E}$ & 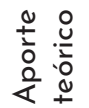 & Ações da Natura \\
\hline \multirow{9}{*}{ 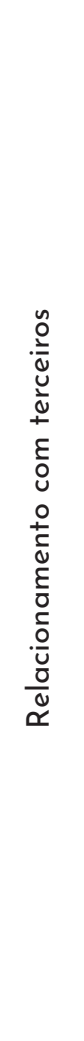 } & \multirow{9}{*}{ 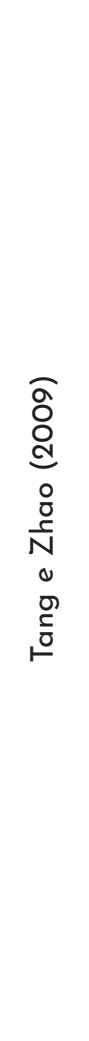 } & $\begin{array}{l}\text { 1999: Foi iniciada a relação com comunidades tradicionais para fornecimento de insumos da } \\
\text { sociobiodiversidade. }\end{array}$ \\
\hline & & $\begin{array}{l}\text { 2000: Iniciou um aprendizado e um trabalho conjunto com as comunidades tradicionais } \\
\text { da floresta para obter os insumos que são utilizados e auxiliar na estruturação de cadeias } \\
\text { sustentáveis de extração de recursos da biodiversidade. }\end{array}$ \\
\hline & & $\begin{array}{l}\text { A cadeia de fornecimento deve garantir, em conjunto com a rede de fornecedores, a quali- } \\
\text { dade socioambiental e a rastreabilidade de toda a cadeia de valor. }\end{array}$ \\
\hline & & $\begin{array}{l}\text { A rede de fornecedores deve estar engajada na implantação e na evolução da visão de } \\
\text { sustentabilidade para que em conjunto possam garantir o desenvolvimento sustentável em } \\
\text { todos os elos da cadeia de valor. }\end{array}$ \\
\hline & & $\begin{array}{l}\text { 2013: Desenvolveu política para uso de material reciclado pós-consumo, abrange a inclusão } \\
\text { das cooperativas de catadores de materiais recicláveis na cadeia de valor, e estabelece } \\
\text { diretrizes para a estruturação de um relacionamento pautado pelo preço justo e equitativo, } \\
\text { capaz de criar oportunidades de negócios sustentáveis para essas comunidades. }\end{array}$ \\
\hline & & $\begin{array}{l}\text { 2014: Busca para a cadeia de fornecimento a rastreabilidade de } 100 \% \text { dos insumos produzi- } \\
\text { dos pelos fabricantes diretos. }\end{array}$ \\
\hline & & $\begin{array}{l}\text { Busca implementar um programa de rastreabilidade para os demais elos da cadeia de valor } \\
\text { da marca Natura. }\end{array}$ \\
\hline & & $\begin{array}{l}\text { 2015: Criação de um indicador IDH-CN com três dimensões: saúde, conhecimentos e padrão } \\
\text { de vida com investimento social nas consultoras Natura e suas famílias. }\end{array}$ \\
\hline & & $\begin{array}{l}\text { 2018: } 165 \text { fornecedores integram o Projeto Qlicar, que se baseia em análises nos pilares Qua- } \\
\text { lidade, Logística, Inovação, Competitividade, Ambiental/Social e Relacionamento. }\end{array}$ \\
\hline \multirow{6}{*}{ 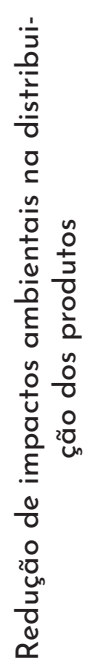 } & \multirow{6}{*}{ 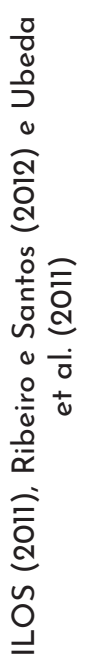 } & $\begin{array}{l}\text { 2011: Desenvolveu uma metodologia de inventário de geração de resíduos para quantificar } \\
\text { o volume gerado nos processos internos, na distribuição dos produtos e no descarte das } \\
\text { embalagens pelos consumidores. }\end{array}$ \\
\hline & & $\begin{array}{l}\text { 2015: Inauguração de um moderno hub logístico, com localização estratégica entre as } \\
\text { plantas industriais, com fácil acesso às principais malhas rodoviárias e aéreas, reduzindo em } \\
\text { duas vezes o número de caminhões utilizados entre as fábricas e } 1 / 3 \text { entre as longas distân- } \\
\text { cias percorridas. }\end{array}$ \\
\hline & & $\begin{array}{l}\text { 2016: Uso de navegação de cabotagem para abastecimento dos centros de distribuição nas } \\
\text { regiões Nordeste e Norte do Brasil reduzindo a utilização do modal rodoviário. }\end{array}$ \\
\hline & & $\begin{array}{l}\text { 2016: Passou a usar alguns veículos de carga elétricos para entrega de produtos a consulto- } \\
\text { ras e consumidores, que emitem nove vezes menos } \mathrm{CO}_{2} \text { do que os veículos convencionais. }\end{array}$ \\
\hline & & 2016: Uso de bicicletas com compartimento de cargas para entregar produtos e revistas. \\
\hline & & $\begin{array}{l}\text { 2018: } 32,8 \% \text { dos resíduos gerados pelas embalagens de produtos foram destinados à recicla- } \\
\text { gem. }\end{array}$ \\
\hline
\end{tabular}




\begin{tabular}{|c|c|c|}
\hline$\stackrel{\varepsilon}{\Psi}$ & 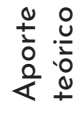 & Ações da Natura \\
\hline \multirow{5}{*}{ 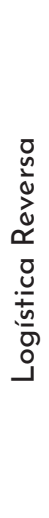 } & \multirow{5}{*}{ 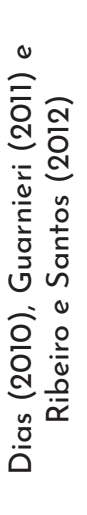 } & $\begin{array}{l}\text { Busca gerar impacto positivo em resíduos com um sistema de logística reversa, que colete e } \\
\text { destine para reciclagem uma quantidade de material pós-consumo maior que a quantidade } \\
\text { gerada pelas embalagens dos produtos. }\end{array}$ \\
\hline & & $\begin{array}{l}\text { Busca implementar um sistema de logística reversa para os produtos Natura na América } \\
\text { Latina. }\end{array}$ \\
\hline & & $\begin{array}{l}\text { Busca coletar e destinar para reciclagem } 50 \% \text { da quantidade de resíduos gerados pelas } \\
\text { embalagens de produtos da Natura no Brasil. }\end{array}$ \\
\hline & & $\begin{array}{l}\text { 2014: Formatou o Projeto Piloto Gerenciador Integrado para conectar, de forma eficiente e } \\
\text { justa, toda a cadeia de logística reversa. }\end{array}$ \\
\hline & & $\begin{array}{l}\text { 2016: Promoveu logística reversa, que incluiu diferentes fontes de captação de resíduos pós- } \\
\text {-consumo, também participou de projeto de logística reversa setorial. }\end{array}$ \\
\hline
\end{tabular}

As práticas evidenciadas pela empresa Natura (Tabela 3) foram classificadas em oito categorias de análise e nestas foram declaradas 50 ações específicas no período abrangido pelo estudo. Observa-se que em 2017 foi reduzida de forma acentuada a quantidade de evidenciações nessas categorias. No entanto, destaca-se que o relatório mudou o foco de evidenciação nesse ano, voltando-se para a apresentação detalhada de novos produtos; para a o crescimento dos negócios realizados nos diversos em que a empresa atua; para o crescimento do e-commerce e da digitalização das vendas, no desenvolvimento das pessoas. Em 2018 retomou o foco dado anteriormente evidenciando indicadores nas diversas áreas de atuação da empresa.

Entre as ações evidenciadas, as voltadas diretamente à Green Logistic foram: redefinir, redução de gases de efeito estufa, reduzir, pegadas de carbono, relacionamento com terceiros, redução de impactos ambientais na distribuição dos produtos e logística reversa, que se consubstanciam em Dias (2010), Ferreira (2011), López et al. (2007) e Ubeda et al. (2011).

\subsection{DISCUSSÃO DOS RESULTADOS}

Ao final da apresentação dos resultados, elaborou-se a Tabela 4, na qual consta elencada a síntese das evidenciações das três empresas pesquisadas. Esta Tabela possibilita a comparabilidade de ações voltadas à Green Logistic entre as empresas. 
Tabela 4

Síntese das evidenciações

\begin{tabular}{lrrrr} 
& \multicolumn{2}{c}{ Quantidade } & \multirow{2}{*}{ Total } \\
\cline { 2 - 4 } & Avoñes Cosméticos & Boticário & Natura & \\
\hline Redefinir & 1 & 13 & 13 & 27 \\
Gases de efeito estufa & 2 & 3 & 3 & 8 \\
Práticas de construção sustentável & 2 & 5 & 0 & 7 \\
Recuperar & 1 & 5 & 6 & 12 \\
Reduzir & 1 & 6 & 5 & 12 \\
Pegada de Carbono & 2 & 0 & 5 & 5 \\
Relacionamento com terceiros & 2 & 9 & 9 & 20 \\
Redução de impactos ambientais na & 1 & 4 & 6 & 11 \\
distribuição dos produtos & 0 & 5 & 5 & 10 \\
Logística Reversa & $\mathbf{1 2}$ & $\mathbf{5 0}$ & $\mathbf{5 0}$ & 112 \\
\hline Total & & 5 & \\
\hline
\end{tabular}

Nota-se, pela visualização da Tabela 4, que as empresas o Boticário e Natura tiveram a mesma quantidade de práticas evidenciadas no período analisado; já para a empresa Avon, as 12 práticas identificadas dizem respeito somente ao relatório de 2014. Apesar dessa discrepância temporal, algumas das ações chamam atenção pela pouca expressividade na empresa Avon, como a "Redefinir". Ampliando a análise, observa-se que todas as empresas evidenciaram a mesma quantidade de categorias, embora com quantidades diferentes de ações realizadas, com exceção da ação "Práticas de Construção Sustentável" na empresa Natura e da "Pegada de Carbono" na empresa o Boticário. Ressalta-se que essas categorias, que representam práticas de sustentabilidade voltadas à Green Logistic, possuem relações diretas e indiretas com a sustentabilidade.

Na categoria "Redefinir", a Avon e a Natura declararam usar sintéticos e não mais realizar testes em animais. Já a empresa o Boticário se concentrou na ecoeficiência das matérias-primas e embalagens. A Natura foi a pioneira em oferecer refil de seus produtos e, na direção da sustentabilidade, preocupou-se com a transparência da rastreabilidade de origem de suas matérias-primas. A Agenda 21 (MMA, 2015), conforme Dias (2010), contempla os 3Rs: reduzir, recuperar e reciclar; e a ISO 14000-Environmental Management (2009) acrescentou outros Rs, como: recuperar, respeitar e redefinir. As ações realizadas pelas empresas estão em consonância com o previsto na literatura, sobre práticas de sustentabilidade, voltadas à Green Logistic.

Com relação à categoria "Gases de Efeito Estufa" as três empresas promoveram ações direcionadas a neutralizar e reduzir a emissão, inclusive no transporte e em toda a cadeia produtiva. Segundo Ribeiro e Santos (2012), essas ações realizadas vão ao encontro das práticas da Green Logistic. Na categoria "Recuperar" as três empresas declararam ações nesta direção, conforme previsto na ISO 14000-Environmental Management (2009), as ações 
envolveram plantio de árvores, criação de reservas naturais e ecoparques e investimentos na Amazônia.

Sobre as "Práticas de Construção Sustentável", as empresas Avon e o Boticário já mencionam ações relacionadas ao conceito de green building promisse, ou seja, com eficiência de utilização de energia, água, recursos naturais e emissão de carbono; apenas a empresa Natura não evidenciou ações nesse sentido. De acordo com o ILOS (2011), uma forma direta de atuação das empresas é o investimento em ativos, visando à redução de emissões, seguindo diretrizes sustentáveis.

A categoria "Reduzir", destacada por Donato (2008) e Agenda 21 (Dias, 2010; MMA, 2015), está lastreada nas três empresas, com ações realizadas de avaliação contínua do impacto ambiental. Ressalta-se que as empresas o Boticário e Natura declararam seus esforços para alcançar a redução de resíduos e rejeitos. Quanto à categoria "Pegada de Carbono", a empresa o Boticário não declarou ações. Em contrapartida, Avon e Natura se comprometeram com a redução de $\mathrm{CO}_{2}$ e utilização de energias renováveis, $100 \%$ limpas, que são consideradas práticas sustentáveis, voltadas à Green Logistic, segundo a Agenda 21 (Dias, 2010; MMA, 2015), a ISO 14000-Environmental Management (2009) e Ribeiro e Santos (2012).

A categoria "Relacionamento com Terceiros" teve mais ações realizadas pelas empresas pesquisadas, entre todas as categorias analisadas, talvez porque esta enseja uma ampla gama de ações, pressupondo parcerias e alianças, operacionais, estratégicas ou gerenciais, das mais diversas naturezas, de forma indireta. Essas ações ratificam o estudo de Tang e Zhao (2009), em que para estes a empresa pode efetuar melhorias no seu relacionamento com terceiros com iniciativas ambientais, sejam prestadores de serviços, sejam concorrentes. As empresas Avon e o Boticário evidenciaram ações relacionadas a parcerias com transportadores e operadores logísticos integrantes da cadeia de valor. No entanto, a empresa Natura articulou parcerias inovadoras, na época, como: com a comunidade, para fornecimento de insumos da sociobiodiversidade; com cooperativas de reciclagem $e$ empresas gerenciadores de resíduos; com fornecedores, visando à incorporação da gestão de sustentabilidade por eles; com toda a cadeia de valor, visando à qualidade socioambiental e rastreabilidade.

A categoria "Redução de Impactos Ambientais na distribuição dos produtos", com forte impacto ambiental, envolve, conforme Ribeiro e Santos (2012) e Ubeda et al. (2011), otimização da rede logística, modais menos poluentes, consolidação de cargas, melhor aproveitamento de veículos e redução do consumo de combustíveis. Nesse sentido, as empresas pesquisadas declararam ações de: criação de centros de distribuição regionais; otimização das opções de envio; redução nas embalagens-caixas de papelão, bandejas e sacos plásticos; e uso de biocombustível. Desse modo, indo ao encontro do sugerido pela literatura como práticas sustentáveis voltadas à Green Logístic. Por fim, a categoria da 
"Logística Reversa", que para Dias (2010), Guarnieri (2011), Ribeiro e Santos (2012) e Ubeda et al. (2011) concentra esforços no retorno dos produtos ou embalagens. Nesse sentido, a empresa Avon não declarou ações, e as empresas o Boticário e Natura evidenciaram esforços para aumentar a coleta de materiais pós-consumo e destiná-los à reciclagem. Nota-se que essa categoria de análise também encontrou lastro com o sugerido pela literatura enquanto práticas de sustentabilidade voltadas à Green Logistic.

Apesar das diversas métricas evidenciadas pelas empresas, mostrando a proatividade delas em vários sentidos da gestão ambiental e sua relação com a Green Logistic, o que é bastante positivo, deve-se destacar a ausência de indicadores que reflitam de forma objetiva a relevância e o significado das referidas métricas. De fato, relacionar essas e outras métricas com outras medidas de atividade da empresa (como faturamento, custo total, benefícios não financeiros, estrutura de ativos e passivos ambientais, etc.) pode produzir uma informação diferenciada na avaliação ambiental da Green Logistic das empresas.

\section{CONSIDERAÇÕES FINAIS}

O estudo buscou responder à seguinte questão de pesquisa: quais práticas de sustentabilidade, voltadas à Green Logistic, são evidenciadas pelas três maiores empresas de cosméticos atuantes no Brasil? A resposta a esse questionamento é de que as práticas são diretamente ou indiretamente voltadas à Green Logistic e apresentadas em suas principais categorias.

As três empresas apresentaram quantidade significativa de evidenciações em praticamente todas as categorias pesquisadas, sendo que a empresa Avon Cosméticos teve a menor quantidade, talvez em razão da análise de um único relatório (ano 2014), com 12 ações, e as empresas o Boticário e Natura com maior quantidade (50 cada uma). Pelos resultados apresentados, nota-se que a empresa que atua há mais tempo na fabricação de cosméticos, entre as três pesquisadas, é a Natura, empresa brasileira fundada em 1969. Também foi a Natura a empresa que teve a primeira prática de sustentabilidade implementada, em 1983, enquanto na empresa Avon Cosméticos ocorreu em 1989. A empresa o Boticário teve essa iniciativa 10 anos após, em 1999.

Comparando as três empresas e as informações evidenciadas nas diversas categorias, nota-se que a empresa Avon Cosméticos ainda não possuía, no período analisado, práticas de sustentabilidade que envolviam a logística reversa, ponto esse que poderá ser uma nova meta ambiental para a empresa. Por outro lado, a empresa o Boticário não teve evidenciações relacionadas a pegadas de carbono, contudo, há sinalizações de que a empresa possui intenções de investir nessa relevante questão ambiental. Por fim, a Natura não teve evidenciações de práticas de sustentabilidade relacionadas à construção sustentável, pela 
qual se entende que o investimento em ativos próprios é uma escolha opcional de cada gestor organizacional.

De forma geral, as empresas pesquisadas apresentaram aplicação de práticas sustentáveis em diversos aspectos, principalmente para o meio ambiente e para a sociedade. Quanto à questão produtiva, evidencia-se que o consumo de matéria-prima, embalagem, energia e relacionamento com a cadeia de suprimento são os focos principais. Ressalta-se que, em geral, as práticas evidenciadas pelas empresas estão em consonância com o previsto pela literatura, enquanto algumas delas são inovadoras.

As limitações do estudo estão alicerçadas na escassez de pesquisas anteriores sobre a temática, o que limita análises comparativas mais robustas, visto a inovação dos temas abordados. Sugestões de pesquisas estão ligadas à construção de métricas e indicadores objetivos para futuras mensurações da representatividade e nível das evidenciações.

Ainda no campo das limitações da pesquisa e sugestões para novos estudos, destacase a não análise de elementos patrimoniais (ativos e passivos ambientais) e a possível incidência de multas ou processos ambientais incorridos pelas empresas. Essas são métricas diretamente relacionadas à gestão e atuação ambiental pelas empresas, as quais, aliadas às informações sobre a certificação ambiental, podem trazer informações relevantes para a avaliação do desempenho ambiental em geral e da Green Logistic em particular das empresas pesquisadas.

\section{REFERÊNCIAS}

As 5 maiores empresas de beleza no Brasil. (2016). Revista Exame. Recuperado de https:// exame.abril.com.br/negocios/as-5-maiores-empresas-de-beleza-no-brasil/

As melhores empresas do Brasil em 2016. (2017). Revista Exame. Recuperado de https:// exame.abril.com.br/revista-exame/500-maiores-empresas/

Associação Brasileira da Indústria de Higiene Pessoal, Perfumaria e Cosméticos. (2018). Notícias da mídia. Recuperado de https://www.abihpec.org.br/

Avon Cosméticos. (2015). Portal eletrônico institucional. Recuperado de http://www.avon. com.brl

Ballou, R. H. (2006). Gerenciamento da cadeia de suprimentos: planejamento, organização e logística empresarial. ( $6^{a}$ ed.). São Paulo: Bookman.

Bardin, L. (1977). Análise de conteúdo. Lisboa: Edições 70. 
Bowersox, D. J., Closs, D. J., \& Cooper, M. (2014). Gestão logística de cadeias de suprimento. ( $4^{a}$ ed.). Porto Alegre: Bookman.

Comissão Mundial Sobre o Meio Ambiente e Desenvolvimento. (1988). Nosso futuro comum. Rio de Janeiro: Fundação Getúlio Vargas.

Corrêa, R., Souza, M. T. S., Ribeiro, H. C. M., \& Ruiz, M. S. (2012). Evolução dos níveis de aplicação de relatórios de sustentabilidade (GRI) de empresas ISE/Bovespa. Sociedade, Contabilidade e Gestão, 7(2), 24-40.

Dias, G. F. (2010). Educação ambiental: princípios e práticas. 9. ed. São Paulo: Gaia.

Donato, V. (2008). Logística verde: Uma abordagem socioambiental. Rio de Janeiro: Ciência Moderna.

Faria, C. A. \& Costa, M. F. G. (2012). Gestão de custos logísticos. São Paulo: Atlas.

Ferreira, H. R., Filho, Pires, J. O. M., Beltrão, N. E. S., Ferreira, A. O., Souza, F. M., \& Campos, L. A. (2011). Logística reversa: Um estudo de caso em uma empresa pública de briquetes no município de Tailândia-Pará. Anais do Encontro da Associação dos Programas de Pós-graduação em Administração, Rio de Janeiro, 25.

Fleury, P. F., \& Ribeiro, A. F. M. (2001). A indústria de operadores logísticos no Brasil: Uma análise dos principais operadores. São Paulo: ILOS.

Gil, A. C. (2002). Como elaborar projetos de pesquisa. (4a ed.). São Paulo: Atlas.

Guarnieri, P. (2011). Logística reversa: Em busca do equilíbrio econômico e ambiental. Recife: Clube de Autores.

Guerra, J., \& Schmidt, L. (2016). Concretizar o wishfull thinking-Dos ODS à COP21. Ambiente \& Sociedade, 19(4), 157-174.

Gupta, S., \& Desai, O. D. P. (2011). Sustainable supply chain management: Review and research opportunities. IIMB Management Review, 23(4), 234-245.

Instituto de Logística e Supply Chain. (2011). Logística verde: Iniciativas de sustentabilidade ambiental das empresas no Brasil. Rio de Janeiro: Relatório da Coleção Panorama ILOS. 
ISO 14000-Environmental Management. (2009). The ISO 14000 family of international standards. ISO Focus. Retrieved from http://www.iso.org/iso/home/standards/management-standards/isol4000.htm

ISO 14020:2000. (2000). Environmental labels and declarations-General principles. Retrieved from https://www.iso.org/obp/ui/\#iso:std:iso:14020:ed-2:vl:en

López, V., Garcia, A., \& Rodriguez, L. (2007). Sustainable development and corporate performance: A study based on the Dow Jones Sustainability Index. Journal of Business Ethics, 75(3), 285-300.

Ministério do Meio Ambiente. (2015). Agenda 21. Recuperado de https://www.mma.gov.br/ responsabilidade-socioambiental/agenda-21

Natura. (2015). Portal eletrônico institucional. Recuperado de http://www.natura.com.br/ www/

o Boticário. (2015). Portal eletrônico institucional. Recuperado de http://www.boticario.com. brl

Okado, G. H. C., \& Quinelli, L. (2016). Megatendências mundiais 2030 e os objetivos de desenvolvimento sustentável (ODS): Uma reflexão preliminar sobre a "nova agenda" das Nações Unidas. bÄru, 2(2), 111-129.

Organização das Nações Unidas. (2019). Cúpula das Nações Unidas sobre o Desenvolvimento Sustentável. Recuperado de https://nacoesunidas.org/pos2015/cupula/

Ribeiro, R. B. \& Santos, E. L. (2012). Análise das práticas estratégicas da logística verde no gerenciamento da cadeia de suprimentos. Revista da Administração da Fatea, 5(5), 20 40.

Shapiro, R. D., \& Heskett, J. L. (1985). Logistics strategy: Cases and concepts. St Paul Minn: West Pub.

Srivastava, S. K. (2007). Green supply-chain management: A state-of-the-art literature review. International Journal of Management Reviews, 9(1), 53-80.

Tang, Q., \& Zhao, X. (2009). Analysis and strategy of the Chinese logistics cost reduction. International Journal of Business and Management, 4(4), 188-191.

Ubeda, S., Arcelus, F. J, \& Faulin, J. (2011). Green Logistics at Eroski: A case study. Int. J. Production Economics, 131, 44-51. 
Vergara, S. C. (2000). Projetos de pesquisa em administração. São Paulo: Atlas.

Wang, F., Lai, X., \& Shi, N. (2011). A multi-objective optimization for green supply chain network design. Decision Support Systems, 51(2), 262-269.

Wang, H., \& Gupta, S. M. (2012). Green supply chain management: Product life cycle approach. International Journal of Production Research, 50(19), 5669-5670.

\section{Como citar este artigo:}

\section{ABNT}

RECH, Mariliza Rech et al. Práticas sustentáveis voltadas à Green Logistic: estudo multicaso em empresas de cosméticos. RACE, Revista de Administração, Contabilidade e Economia, Joaçaba: Editora Unoesc, v. 18, n. 3, p. 419-446, set./dez. 2019. Disponível em: http:// editora.unoesc.edu.br/index.php/race. Acesso em: dia/mês/ano.

\section{APA}

Rech, M., Gomes, D. G. de, Reckziegel, V., \& Souza, M. A. de. (2019). Práticas sustentáveis voltadas à Green Logistic: Estudo multicaso em empresas de cosméticos. RACE, Revista de Administração, Contabilidade e Economia, 18(3), 419-446. Recuperado de http://editora.unoesc.edu.br/index.php/race 